\title{
Prevalence and etiology of thyroid disease: A review
}

\author{
Naheed Shah ${ }^{1}$, Tahira Jabeen Ursani ${ }^{1}$, Nadir Ali Shah ${ }^{1}$ and Hafiz \\ Muhammad Zeeshan Raza ${ }^{2 *}$ \\ 1. Department of Zoology, University of Sindh, Jamshoro, 76080, Sindh-Pakistan \\ 2. Genomics and Computational Biology Laboratory, Biosciences Department, COMSATS University Islamabad, \\ Sahiwal Campus, Punjab-Pakistan \\ *Corresponding author's email: hafizraza26@gmail.com \\ Citation \\ Naheed Shah, Tahira Jabeen Ursani, Nadir Ali Shah and Hafiz Muhammad Zeeshan Raza. Prevalence and etiology of \\ thyroid disease: A review. Pure and Applied Biology. Vol. 10, Issue 3, pp691-702. \\ http://dx.doi.org/10.19045/bspab.2021.100071
}

\begin{tabular}{llll}
\hline \hline Received: 01/08/2020 & Revised: 29/10/2020 & Accepted: 05/11/2020 & Online First: 26/11/2020
\end{tabular}

\section{Abstract}

Hypothyroidism and hyperthyroidism are the major thyroid disorders caused due to malfunctioning of the thyroid gland. Thyroid diseases have been observed in more than 100 countries and affecting approximately 1.6 billion populations worldwide and people are many at risk and desperately need iodine supplementation. Thyrotoxicosis is the term mostly used for hyperthyroidism, but not all the cases of hyperthyroidism signify thyrotoxicosis. Hypothyroidism and hyperthyroidism are caused because of low or high production of thyroid hormones. Causes of hyperthyroidism are thyroid hyperplasia related to Graves` disease, high intake of thyroid hormones, multi nodular goiter and hyper functional goiter and thyroid adenoma. Other causes of hyperthyroidism may include thyroiditis, pituitary adenoma secreted by TSH and high secretion by ectopic thyroid. Deficiency of iodine usually causes hypothyroidism. Iodine salt plays integral role in hypothyroidism as well as hyperthyroidism. Need of iodine is compensated by water and foods if there is deficiency in sources of iodine, then it results in malfunctioning of thyroid gland resulting in development of cretinism, hypothyroidism and many other iodine related issues. The thyroid disease and its prevalence vary from country to country. The prevalence of hyperthyroidism in Pakistan was observed to be $5.1 \%$ while sub clinical hyperthyroidism accounted for 5.8\%, however hypothyroidism was observed to be $4.1 \%$ and $5.4 \%$ in case of sub clinical hypothyroidism respectively. In females the prevalence of hypothyroidism, hyperthyroidism, sub clinical hyperthyroidism as well as sub clinical hypothyroidism was higher in female population as compared to the males.

Keywords: Hypothyroidism; Hyperthyroidism; Iodine; Thyroid disorders; Thyrotoxicosis; Thyroid glands

\section{Introduction}

Enlargement of the thyroid and abnormalities in the thyroid gland's normal functioning is referred to as thyroid diseases/disorders. The major abnormalities of thyroid glands are hypothyroidism (low production of thyroid hormones) and hyperthyroidism (high secretion of thyroid hormones) [1]. Every abnormality of thyroid has its own symptoms and manifestations. According to reports globally almost 1.6 billion people are at the risk of thyroid disorders and needs 
supplements of iodine. Thyroid diseases have been reported all across the world in more than hundreds of countries including developing as well as under developed countries of the continent Africa, Asia, and America etc. In Pakistan the population which is iodine deficient accounts for 20 million, while 8 million shows many iodine deficiency disorders (thyroid malfunctioning) and approximately 1 million people are suffering from mental problems [1].

\section{Pathophysiology of thyroid gland and its hormones}

The thyroid is butterfly shaped small gland with 20 to 25 grams of weight [2]. It has two major hormones, namely T3 (triiodothyronine) and T4 (thyroxin). Thyroid follicles secrete thyroxin or T4 hormone. The basic structure of $\mathrm{T} 3$ and $\mathrm{T} 4$ is almost identical, consisting of two tyrosine (amino acid) linked with each other. T3 hormone has three iodine atoms known as triiodothyronine, while T4 has four iodine atoms named as thyroxin [3]. During the normal functioning thyroid gland secretes T3 and T4 approximately $7 \%$ and $93 \%$, respectively. Nevertheless, the potency of T3 is greater than T4 about 3 to5 folds [4]. TSH (Thyroid stimulating hormone) is secreted by the stimulation of TRH (tripeptide-releasing hormone) by the hypothalamus. TSH is also called thyrotropin, which is anterior pituitary hormone and involved in synthesis, regulation and secretion of synthesis of T3 and T4 hormones [5].

TSH is involved in controlling the release of T3 and T4 according to the requirements. The abnormal TSH concentrations may result in various thyroid disorders, which may result in many thyroidal as well as non-thyroidal disorders. The condition of primary hypothyroidism presents high serum levels of TSH while low T3 and T4 levels. In the case of mild hypothyroidism, the level of TSH is observed to be high but T4 level may be normal [6]. Likewise, the condition of hyperthyroidism presents high serum levels of T3 and T4 and low level of TSH because of negative feedback mechanism [7]. Thyroid hormone affects almost all the cells and organs of the body including thyroid gland, uterus, testes, and spleen, except the adult brain. Usually, thyroid gland and its hormones are involved in the stimulation of the enzyme associated with oxidation of glucose and thus cause the increase in rate of basal metabolic rate and production of heat. During the development of fetal and in the early postnatal life [8]. The high and abnormal secretion of these hormones cause $60 \%-100 \%$ increase in rate of basal metabolism which will also increase the rate of food metabolism, synthesis and catabolism of proteins. The stimulation to the brain also increases and functioning of various endocrine glands also increased. In children high skeletal growth is caused by hyperthyroidism making a child taller considerably. Conversely greatly low growth rate is associated with hypothyroidism. If the child deficient with iodine is not provided with thyroid therapy after birth then it may suffer from mental retarding and insufficiency for lifetime. Above all the thyroid hormones have also major definite effects on vital mechanisms of body as well [9].

\section{Hypothyroidism}

Low serum level and secretion of thyroid hormones are termed as hypothyroidism. Hypothyroidism is characterized by the inability of thyroid gland to produce required level of hormones. Iodine is necessary for the synthesis of thyroid hormones. The unavailability of iodine leads to the development of hypothyroidism. Mostly hypothyroidism develops due to iodine deficiency, but it may also develop due to low TSH secretion, chronic lymphocytic thyroiditis or/and Hashimoto's disease but in rare cases. Malfunctioning of the pituitary 
gland may cause low TSH level, which may be due to antithyroid drugs [10].

Low serum thyroid hormones level may be due to various exogenous as well as endogenous abnormalities. Low iodine intake is one of the exogenous causes of hypothyroidism. The example of an exogenous cause of hypothyroidism is endemic goiter. The endogenous causes include autoimmunity against the thyroid gland, leading towards the gland destruction instead of stimulation. The example of endogenous cause of hypothyroidism is Hashimoto's disease [4].

In the early stages, symptoms of iodine deficiency are body weakness, fatigue, constipation, coarse and dry skin, cold intolerance, slow or low rates of metabolism [11]. Depression is the primary psychological symptom of hypothyroidism. These are the symptoms experienced by the majority of the people suffering from severe hypothyroidism [12]. The prolonged deficiency of iodine results in seizing synthesis of thyroid hormones by thyroid gland leading toward high TSH production by pituitary gland. TSH stimulates the thyroid gland to get iodine, resulting in hyperplasia of the thyroid gland up to 300 to500 grams. In many countries of the world, due to insufficiency of iodine in water and soil the grown food is also iodine deficient and the native of those areas are unable to get the required amount of iodine and suffer from the development of goiter known as endemic goiter [13].

\section{Cretinism}

During infancy and early fetal life, development of severe hypothyroidism is known as cretinism, and diagnosis within weeks of birth can help in its prevention. It is also known as endemic cretinism in iodine deficient areas. Its causes may growth failure of thyroid, inadequate synthesis of hormones because of unavailability of iodine, dietary goitrogenic and deficiency of autosomal recessive enzyme known as sporadic cretinism. The clinical manifestations of cretinism are stocky and short physique, thick neck and tongue, and mental retardedness. These conditions are not irreversible [14].

\section{Myxedema}

Myxedema is characterized by a deficiency of thyroid hormones in adulthood showing edematous appearance on the whole body [15]. Voice hoarseness, skin roughness, and enlargement of heart are major manifestations of myxedema. The leading causes are low TSH serum levels, destruction of the thyroid by Hashimoto's, autoimmune thyroiditis, antithyroid drugs therapy, inability to synthesize thyroid hormones due to iodine deficiency and gland ablation by surgery [16].

\section{Iodide goiter}

Iodide goiter is a condition with or without hypothyroidism developed due to excess and chronic iodine consumption [17]. Clinical manifestation includes enlarged goiter. The iodide goiter prevalence in America was about 5 to $10 \%$ [18]. Patients with respiratory disorders are more prone to have iodide goiter. Nonetheless, it is rarely reported and is also associated with dysfunction of the thyroid gland [19].

\section{Multinodular and diffused goiter}

Multinodular and diffused goiters are very rare. Their causative reason is the innate defect in enzymatic function but in many cases the exact cause is still unknown. These are sometimes considered as two different goiters based on symptomatic phases during the pathological process. Multinodular goiter is characterized by asymmetrical shape and with irregular radio uptake, while diffused goiter has a symmetrical shape with diffused uptake [20].

Food deficiency of iodine is the main reason of developing hypothyroidism which occurs mostly during phases of development and growth with inadequate dietary iodine. Mostly the pregnant females and their babies are affected [21]. 


\section{Causes of goiter}

Hashimoto's disease, commonly known as lymphocytic thyroiditis, is characterized by low production of thyroid hormones because of thyroid cells destruction. Usually, the cancer treatment involves the removal of the thyroid gland and partial thyroidectomy in the condition of hyperthyroidism that can also result hypothyroidism. Goiter can also be developed in pregnancy due to thyroid inflammation, goitrogenic substances and viral illness. Goitrogenic substances are present in plants like rape seeds, cassava, cabbage, turnip, mustard [22].

Many antithyroid drugs including thiocyanates, propylthiouracil, and inorganic iodide therapy for the treatment of hyperthyroidism can also result in developing goiter [23].

Failure of the pituitary gland also leads to Hypothyroidism (secondary hypothyroidism), but it is not common. Innate enzymatic errors in metabolism of iodine, increase TSH production, defected receptors of thyroid hormone, thyroid glands autoimmunity and malignancy are also some rare cases. Iodine deficiency was found in more than $90 \%$ of the goiter patients. Thyroid diseases if remains untreated, can seriously effects the body [24].

\section{Prevalence of hypothyroidism}

Prevalence of hypothyroidis ranges from 5\% to $15 \%$ in various areas. In Khyber Pakhtunkhwa province, Pakistan, approximately $70 \%$ of the rural population and more than $50 \%$ of urban population is encountering various disorders due to deficiency of iodine. According to a survey in Peshawar schools the prevalence of goiter was $59 \%$ in children with ages less than 10 years. The palpable goiter in Kalam was reported to be $21.18 \%$ [25]. The deficiency of iodine and its related disorders are major health problems of the whole country more commonly in less developed areas like Hazara, Dir, Malakand and Chitral etc. [26].
In Islamabad, the prevalence of severe iodine deficiency was also reported and goiter accounted for $62.1 \%$ in children with school going ages. The clinical examination of children showed goiter of grade1 and 2 in $39.27 \%$ of children [27]. In Pakistan hypothyroidism accounted for $4 \%$, while $5.4 \%$ with subclinical hypothyroidism amongst thyroid patients as reported by Akhtar [28]. Out of which in males, the prevalence of hypothyroidism was $1.3 \%$ and in females, it was $2.75 \%$ respectively. Likewise, in male population, $1.5 \%$ suffered from subclinical hypothyroidism and in females it was observed to be $3.9 \%$. In Southern China areas of cretinism and endemic goiter impaired occular hearing was found in normal school children with age range of 7 to 11 years due to deficiency of iodine treated with iodized salt [29]. Chiovato [30] reported hypothyroidism in transient neonates because of the deficiency of iodine in third world countries, Italy and Europe.

According to Mengreli [31] in 1979 in Greece, screening of 1274000 neonates was done, out of which 377 have congenital hypothyroidism. The study conducted by Shankar [32] in North India specifically areas deficient with iodine to explore hypothyroidism and its causes in children. He found in 54\% of children there was found significant growth retardation.

A survey conducted by Foo [32]in Ai river and Lemanak villages to found the prevalence of goiter showed high prevalence $36.9 \%$ among villagers living in iron deficient soil areas and $26.5 \%$ in the interior Ai river area. The prevalence was much higher among young females $75.4 \%$ as compared to older ones $49.1 \%$.

The deficiency of iodine can be prevented making the irrigation water iodinated. This technique was used to increase the iodine content of the soil, water, crops, humans and animals in Xinjian province of China. 
Making the water iodinated is one of the simplest, easy, cost effective as well as effective methods [33]. Before the $2^{\text {nd }}$ world war, deficiency of iodine was also reported and the prevalence was accidentally reduced because of large milk and dairy product consumption contaminated with iodine resulting in a decline of hypothyroidism cases.

\section{Hyperthyroidism}

A high serum level of thyroid hormones is referred as hyperthyroidism, which is usually due to exogenous or endogenous agents. The endogenous causes of hyperthyroidism include autoimmune abnormalities of the thyroid gland in which the cells producing thyroid hormones are stimulated for abnormally high secretions. Examples of endogenous causes are thyroid glands adenoma and Graves' disease. Hyperthyroidism is also developed due to high iodine intake or excessive thyroid hormones ingestion. Thyrotoxicosis is a term generally used for hyperthyroidism, but as already mentioned that all the cases of hyperthyroidism did not represents symptoms of thyrotoxicosis. It is usually developed in middle ages. The clinical basic manifestation of thyrotoxicosis or hyperthyroidism presents hyperplasia of thyroid gland with the size 2-3 times more than normal. The secretion rate also increases 5 to 15 times by each cell resulting in diminish of TSH in serum. Commonly observed symptoms are loss in weight loss with high appetite, tremors, body weakness, tachycardia, nervousness, loose stools, goiter, anxiety, irritability, exophthalmos, heat intolerance, heavy sweating and moist and warm skin $[5,34]$

\section{Thyrotoxicosis}

Thyrotoxicosis is characterized by high levels of T3 and T4 in the blood in free form resulting in high rate of metabolism. As it is also developed by high activity of the thyroid gland, so it is also known as hyperthyroidism.
Conversely, in many states and in thyroiditis the increased secretion is responsible for hyperthyroidism instead of gland hyperfunctioning. So, it can be said that thyrotoxicosis is a type of hyperthyroidism. Primary hyperthyroidism and secondary hyperthyroidism are the terms used based on intrinsic or extrinsic thyroid abnormalities like a pituitary tumor.Thyroid gland diffused hyperplasia along with Graves' disease is the most common cause of hyperthyroidism. Other causes are hyperfunctional multinodular goiter and thyroid hyperfunction adenoma. Uncommon causes are thyroiditis, pituitary adenoma and ectopic thyroid secreting high concentration of hormone in ovarian tetramas [35].

Graves' disease is the autoimmune disease in which the body starts producing antibodies against thyroid resulting in high thyroid hormones level, causing ineffictivity of feedback mechanism, which otherwise controls the normal thyroid secretion [36]. Antibodies or immunoglobulin acts like TSH and were observed in almost $50 \%$ to $80 \%$ thyrotoxic patient's blood. Autoimmune thyroiditis and Graves' disease belongs to same genetic family so genetic factors are involved [37]. High intake of iodine also induces the development of hyperthyroidism or thyrotoxicosis in individuals who were previously iodine deficient. Jod-basedow or Iodine induced thyrotoxicosis (IIT) is the toxic effect of excess iodine [38].

\section{Iodine induced hyperthyroidism (IIH)}

Many mutational changes in the thyroid cells lead towards Iodine induced hyperthyroidism and making the cells autonomous. With the growth of these cells the supply of iodine increases, making a person thyrotoxic [39]. The females in their young and middle age develops defuse enlargement of the thyroid gland which is painless and is known as autoimmune thyroiditis/Hashimoto's thyroiditis/ /chronic thyroiditis and lymphocytic thyroiditis [40]. 
In areas deficient in iodine high prevalence of Hashimoto's thyroiditis has been reported, where introduction of supplementation enrich in iodine has been adopted [41, 42]. Hashimoto's thyroiditis may be caused due to many factors like hyperplasia of the thyroid gland which is commonly induced by repletion, deficiency or excess of iodine. Hashimoto's thyroiditis can be categorized as the type of autoimmunity I which antibodies produced against cells of thyroid. Mostly patient's serum had auto-antibodies. Lymphocytic infiltration occurs in the thyroid gland which causes the destruction of thyroid cells. On the other hand, patients diagnosed with mild hypothyroid or euthyroid rarely became hyperthyroid [43, 44].

Thyrotoxicosis or hyperthyroidism can also be developed due to consumption of drugs, topical antiseptics and diagnostic materials containing iodine like dyes used in radio contrast, vitamins supplements, tablets for purification of water, various kelp with iodine, and amiodarone etc. [45]. It may also be because of tumor or localized adenoma developed in the thyroid glands and its cells which start secreting abnormally high concentrations of thyroid hormones [46].

\section{Hashimoto's disease or autoimmune thyroiditis}

It is also reported in the areas deficient with iodine in soil and water and after seeking the iodine therapy in individuals. According to Foley [37] Hashimoto's disease was uncommon in people living in, dietary deficient areas for iodine. Thyroiditis (autoimmune disease) significantly increased after getting iodine therapy, iodized salt administration, and consumption of oil and bread. After the intake of dietary iodine, thyroid gland lymphocytic infiltration occurred. However, antibodies were not found in serum of patients with endemic goiter, and $43 \%$ of people after iodized oil therapy developed hyperthyroidism. The iodine diet and medication also increased the severity and frequency of autoimmune thyroid diseases. In goiter treatment with lugol's iodine, thyrotoxicosis had also been observed to be developed. Thyrotoxicosis was caused by iodine used as a source [47]. Enlargement of the thyroid gland was observed after chronic use of drugs like hydroxyquinoline and lugol's iodine [48]. Iodine-rich drug amiodarone was also associated with the development of thyrotoxicosis [49].

According to report iodide goiter, can also be developed after long therapy of iodide or iodide producing compounds. Excess amount of iodine in the daily diet of the normal person can also produce iodide goiter [50]. It was observed that individuals with no thyroid abnormalities other than euthyroid after treatment with iodine supplementation medication developed iodine induced thyrotoxicosis and iodine cessation; again euthyroid status was restored [51]. High iodine doses are not recommended to goiter and thyroid patients except in case of iodine deficiency [52]. The increase in T4 level in a patient with toxic adenoma after taking potassium iodide was observed. The goiter was evaluated in pregnant females of Bangladesh rural areas before starting the iodine supplementation and the prevalence of goiter was recorded as $99 \%$. So, it can be concluded that high prevalence of goiter can occur even without severe deficiency of iodine and supplementation of iodine may also not entirely solve the problems of goiter [53].

Prevalence of thyrotoxicosis/hyperthyroidism

In Pakistan thyrotoxicosis is very rare. Nevertheless, patients with other thyroid disorders have been reported to have thyrotoxicosis or hyperthyroidism. In order to develop a proper health care system regarding thyroid disorders it is necessary to have the knowledge, planning as well as 
assessment of thyroid disease its prevalence in accordance with hormone levels and intake of iodized salt. The pattern of thyroid diseases in Ethiopia was studied by selecting 373 patients in an endocrine clinic. In $43.9 \%$ patients thyrotoxicosis, in $23.6 \%$ euthyroid solitary nodules, in $22.3 \%$ simple goiter and in $6.7 \%$ Euthyroid multinodular goiter was observed. However, the prevalence of thyrotoxicosis in cases of Graves' disease accounted for $41.7 \%, 31.9 \%$ with toxic multinodular goiter, $22.1 \%$ with toxic solitary nodule, $3.1 \%$ with Base dow's goiter and $1.2 \%$ had thyroiditis [54].

In Zimbabwe, hyperthyroidism had also been reported after the consumption of iodized salt. Urinary iodine concentration was observed to be increased by 10 folds. Some reports also documented the increase in cases of toxic nodular goiter with ages more than 40 year after salt iodization [45]. Miller and Block conducted a research on 70 patients of multinodular goiters In Michigan to investigate the function of thyroid and concluded that with the increase in age there was also observed an increase in autonomous tissues which led towards euthyroid to condition of hyperthyroidism [55].

Iodine in high concentrations is toxic and cause thyrotoxicosis. Patients with thyrotoxicosis history should avoid supplementation of dietary iodine. Many researches also recommended avoiding iodized salt until prescribed $[41,56]$. Gomez [57] conducted research on thyroid nodular disease in 110 elderly patients and observed a yearly incidence of $0.4 / 1000$ peoples. Out of 110 research subjects, hyperthyroidism was found in $58.2 \%$ out of which $53.1 \%$ had T4 thyrotoxicosis, T3 thyrotoxicosis was observed in $12.5 \%$, subclinical hyperthyroidism in $34.4 \%$ and iodine induced hyperthyroidism $8.2 \%$ patients. Lavard [58] reported thyrotoxicosis was confirmed in Denmark in 56 children with ages less than 5 years. $0.79 / 100,000$ was the rate of prevalence of thyrotoxicosis in the population. They claimed thyrotoxicosis as a rare disorder however women showed 6.7:1 tendency of hyperthyroidism as compared to males.

The effect of iodine on thyrotoxicosis was studied by [59] and its prevalence was observed to be increased after taking iodized salt, and was highly prevalent in females. The residents of Hokkaido, Japan Island consumed were high iodine containing seaweed. In Tasmania, Australia the increase in the prevalence of thyrotoxicosis induced by iodine was reported [59, 60]. Iodine supplementation of bread in Tasmania was initiated in 1966 to correct moderate iodine deficiency. A prospective study conducted in a normal iodide area on 242 non-toxic nodular goiter patients revealed in patients with autonomous tissues had a high $75 \%$ subclinical hyperthyroidism prevalence, while subjects without autonomous tissues had low $17.2 \%$ subclinical hyperthyroidism [61].

The thyroid disorders and its frequency in different age groups, gender based and different climatic conditions was studied [28] in Pakistan and revealed that percentages of subclinical hyperthyroidism as well as hyperthyroidism in different age groups were found to be $5.1 \%$ to $5.8 \%$, with high prevalence rates in women as compared to men $(3.85 \%$ vs. $1.2 \%)$. Likewise, in case of subclinical hyperthyroidism it was observed to be $(4.3 \%$ women vs $5 \%$ men $)$ high in women.

\section{Thyroid problems in accordance with role of iodine}

In thyrotoxicosis, hyperthyroidism, hypothyroidism and other thyroid disorders, iodine plays a major role. Iodine the integral component of thyroid hormones it greatly affects hormones production by thyroid gland. Water and food is the main source of iodine, deficiency of iodine in major dietary sources rendered towards the adaptation of 
iodine supplementation. If deficiency of iodine occurs and food provides an insufficient amount of iodine it results in hypothyroidism including cretinism. Correspondingly high intake of iodine as iodized bread, salt or oil can also produce thyrotoxicosis or hyperthyroidism induced by iodine. In elderly patients with nodular goiter small amount of iodine introduction to severely iodine deficient individuals had been associated with the induction of hyperthyroidism [62].

Iodine intake is usually high in plains and coastal regions as compared to the iodine intake in mountain areas. Moreover, as disinfectant iodine and iodine containing compounds are used. It is also used in processing of milk and cleaning of storage tanks for water, which may be the cause of increased contents of iodine in milk and water. In the feed of livestock, iodine is present as a major ingredient which also enhances consumer's iodine level. The iodine mixed in commercially available salts is highly variable. Many manufacturers add iodine without knowing exact concentration leading towards the irregular distribution of iodine in salt. Typically, manufacturers of salt do not have any relevant personnel and mixing arrangement. So, the consumption of that salt raises uncertain levels of iodine in consumers [63].

High concentration of iodine can be tolerated by most of humans but some people are sensitive to iodine and little excessive amount of iodine consumption in them may develop various untoward responses. That is why it is contraindicated in iodine sensitive patients to consume iodine supplementation and in patients of thyrotoxicosis [63]. The growth as well as the development of humans and also animals is greatly affected by the deficiency of iodine. The undesired effects due to iodine include low birth weight, fetus death, reproductive failures, and young ones without hairs. The prevalence of iodine deficiency is significantly controlled by use of iodine supplementation in various countries worldwide [64]. Iodine plays a vital and compulsory role in the production, synthesis and release of thyroid hormones. Therefore solid knowledge about the use, distribution, and metabolism is necessary in order to recommend daily dose of iodine for treating and managing various iodine deficiency thyroid disorders.

\section{Iodine supplementation}

Iodine deficiency disorders are treated and can be prevented by supplementation of iodine. Iodine is readily metabolized by the body and cannot be stored. So, iodine must be consumed $\mathrm{n}$ diet regularly. Iodized salt is the major source of iodine supplementation. As the supplementation containing iodine is a common method but it takes a long time for implementation, for short time implementation iodized oil capsules are also recommended to treat severe iodine deficiency. Various food items, including sweets, water, bread, milk, and sugar, were also as a source of iodine. But the use of salt is most common method to teat iodine deficiency due to its universal availability, cost effectiveness and universally consumed product irrespective of eating habits of the community for life time [65].

Pakistan is also facing various disorders of iodine deficiency, to encounter its effects the government and health ministry is trying to treat and eliminate IDD from the country by using universal salt iodization. In this context in 1995, legislation was approved by the National Assembly, which made it mandatory the iodization of table salt for all salt manufacturers. The recommended iodine concentration of $70 \mathrm{ppm}$ in the form of sodium iodate or iodide was recommended (Table 1). But research suggested that iodized salt do not have iodine as per recommendations.

A research was conducted on school going children in North-West Poland to evaluate 
the consumed and urinary salt concentration in relation to goiter incidence. The research revealed that only $11.2 \%$ of children were taking iodized salt. Mild deficiency of iodine was reported with the mean values of iodine concentration to be $76.2 \mu \mathrm{g} / \mathrm{L}$ in consumers and non-consumers of iodized salt. $12.9 \%$ goiter incidence was also found [66]. In 1981 in Italy $47.1 \pm 22.4 \mathrm{mg} / \mathrm{Kg}$ was observed to be the mean urinary iodine excretion, while $60 \%$ prevalence of goiter was also reported. In 1991 the mean urinary iodine excretion level increased and was $129.7 \pm 73 \mathrm{mg} / \mathrm{Kg}$ with drop of prevalence rate of goiter to $8.1 \%$ only [67].

Table 1. Recommended daily dose of iodine

\begin{tabular}{|c|c|}
\hline Age & Daily iodine dose $(\boldsymbol{\mu g})$ \\
\hline Pregnancy & 175 \\
\hline Lactation & 200 \\
\hline $0-6$ months & 40 \\
\hline 6-12 months & 50 \\
\hline $1-10$ years & $70-120$ \\
\hline 11 years (Adult) & $120-150$ \\
\hline
\end{tabular}

\section{Recommended daily allowances of iodine} The need of the body determines the requirement of nutrition. The need of iodine in body depends on the body growth, gender, weight, age, disease, nutrition and climate. $150 \mu \mathrm{g}$ iodine is the normal requirement for healthy adult daily, approximately $50 \mathrm{mg}$ or 1 Tsp iodine each year for life time is required to accomplish sufficient synthesis and release of thyroid hormones. The tolerable or normal range of iodine intake is $50-1000 \mu \mathrm{g}$ which is safe for a normal adult [22]. Requirement of iodine in children increases with the increase in age. The mean values of iodine dose for healthy person along with age are given below [68].

\section{Conclusion}

Thyroid disorder is the major health issue with high prevalence in different countries. The low and high iodine concentration in the blood develops thyroid disorders known as hypothyroidism and hyperthyroidism. So the level of iodine needs to be monitored to prevent thyroid related disorders. It these disorders remain untreated, it may affect the whole body. Consumption of iodized salt is one of the easiest ways to prevent thyroid disorders.
Authors' contributions

Conceived and designed the experiments: NA Shah, Performed the experiments: N Shah \& NA Shah, Analyzed the data: TJ Ursani, Contributed materials/ analysis/ tools: N Shah \& TJ Ursani, Wrote the paper: N Shah \& HMZ Raza.

\section{References}

1. Taylor PN, Albrecht D, Scholz A, Gutierrez G, Lazarus JH, Dayan CM \& Okosieme OE (2018). Global epidemiology of hyperthyroidism and hypothyroidism. Nat Rev Endocrinol 14(5): 301.

2. Ogbera AO \& Kuku SF (2011). Epidemiology of thyroid diseases in Africa. Indian J Endocrinol Metab 15(Suppl2): S82.

3. Devereaux D \& Tewelde SZ (2014). Hyperthyroidism and thyrotoxicosis. Emerg Med Clin 32(2): 277-292.

4. Hoang T, Mai V, Clyde P \& Shakir M (2013). Over-the-counter-drug-induced thyroid disorders. Endocr Pract 19(2): 268274.

5. Leung AM \& Braverman LE (2014). Consequences of excess iodine. Nat Rev Endocrinol 10(3): 136-142.

6. Stagnaro Green A \& Pearce E (2012). Thyroid disorders in pregnancy. Nat Rev Endocrinol 8(11): 650-658. 
7. Zimmermann MB \& Boelaert K (2015). Iodine deficiency and thyroid disorders. Lancet Diabetes Endocrinol 3(4): 286-295.

8. Basu G \& Mohapatra A (2012). Interactions between thyroid disorders and kidney disease. Indian J Endocrinol Metab 16(2): 204.

9. Jong JAF, Verkooijen HM, Valk GD, Zelissen PMJ \& Keizer B (2013). High failure rates after 131I therapy in Graves hyperthyroidism patients with large thyroid volumes high iodine uptake and high iodine turnover. Clin Nucl Med 38(6): 401-406.

10. Unnikrishnan AG \& Menon UV (2011). Thyroid disorders in India: An epidemiological perspective. Indian $J$ Endocrinol Metab 15(Supp12): S78.

11. Burch HB, Cooper DS, Garber JR, \& Greenlee MC Montori VM (2011). Hyperthyroidism and other causes of thyrotoxicosis: management guidelines of the American Thyroid Association and American Association of Clinical Endocrinologists. Thyroid 21(6): 593-646.

12. Petersen M, Bulow PI, Knudsen N, Andersen S, Jorgensen T, Perrild H \& Carle A (2019). Changes in subtypes of overt thyrotoxicosis and hypothyroidism following iodine fortification. Clin Endocrinol (Oxf). 91(5): 652-659.

13. Bogazzi F, Tomisti L, Bartalena L, Aghini LF \& Martino E (2012). Amiodarone and the thyroid: a 2012 update. J Endocrinol Invest 35(3): 340-348.

14. Pearce EN (2015). Thyroid disorders during pregnancy and postpartum. Best Pract Res Clin Obstet Gynaecol 29(5): 700-706.

15. Ross DS (2011). Radioiodine therapy for hyperthyroidism. $N$ Engl J Med 364(6): 542-550.

16. Menconi F, Marcocci C \& Marino M (2014). Diagnosis and classification of Graves' disease. Autoimmun Rev 13(4-5): 398-402.

17. Rhee CM, Bhan I, Alexander EK \& Brunelli SM (2012). Association between iodinated contrast media exposure and incident hyperthyroidism and hypothyroidism. Arch Intern Med 172(2): 153-159.

18. Santos RB, Romaldini JH \& Ward LS (2012). A randomized controlled trial to evaluate the effectiveness of 2 regimens of fixed iodine (131I) doses for Graves disease treatment. Clin Nucl Med 37(3): 241-244.

19. Kandi S \& Rao P (2012). Anti-thyroid peroxidase antibodies: Its effect on thyroid gland and breast tissue. Ann Trop Med Pub Heal 5(1): 1.

20. Kitahara CM, Gonzalez AB, Bouville A, Brill AB, Doody MM, Melo DR \& Villoing D (2019). Association of radioactive iodine treatment with cancer mortality in patients with hyperthyroidism. JAMA Intern Med 179(8): 1034-1042.

21. Wong KK, Shulkin BL, Gross MD \& Avram AM (2018). Efficacy of radioactive iodine treatment of graves' hyperthyroidism using a single calculated 131 I dose. Clin Diabetes Endocrinol 4(1): 1-8.

22. Chandna S \& Bathla M (2011). Oral manifestations of thyroid disorders and its management. Indian J Endocrinol Metab 15(Suppl2): S113.

23. Narayana SK, Woods DR \& Boos CJ (2011). Management of amiodarone-related thyroid problems. Ther Adv Endocrinol Metab 2(3): 115-126.

24. Vanderpump MPJ (2011). The epidemiology of thyroid disease. $\mathrm{Br} \mathrm{Med}$ Bull 99(1).

25. Talat A, Khan AA, Nasreen $S$ \& Wass JA (2019). Thyroid Screening During Early Pregnancy and the Need for Trimester Specific Reference Ranges: A CrossSectional Study in Lahore Pakistan. Cureus 11(9).

26. Sajid N, Riaz M, Fawwad A \& Basit A (2019). Thyroid dysfunction in subjects with type 1 diabetes at a tertiary care unit of Karachi Pakistan. Clin Epidemiol Glob Heal 7(3): 435-438.

27. Ahmad T, Khoja A, Rashid NH \& Ashfaq MA (2018). Outcome of radioactive iodine therapy in Toxic Nodular Goiter in Pakistan. Pak J Pharm Sci 34(5): 1146.

28. Naz N, Rizvi S \& Sadiq Z (2017). Assessment of thyroid hormone levels and thyroid disorders: A case study from Gujranwala Pakistan. Pak J Pharm Sci 30(4).

29. Rehman R, Zafar A, Fatima SS, Mohib A \& Sheikh A (2020). Altered Sperm Parameters and Subclinical hypothyroidism; a cross 
sectional study in Karachi Pakistan. Int $J$ Clin Pract e13555.

30. Attaullah S, Haq BS \& Muska M (2016). Thyroid dysfunction in Khyber Pakhtunkhwa Pakistan. Pak J Med Sci 32(1): 111.

31. Bose A, Sharma N, Hemvani N \& Chitnis DS (2015). A hospital based prevalence study on thyroid disorders in Malwa region of Central India. Int J Curr Microbiol App Sci 4(6): 604-611.

32. Gessl A, Lemmens GR \& Kautzky WA (2013). Thyroid disorders. In Sex and Gender Differences in Pharmacology (pp. 361-386). Springer.

33. Ahmed RG (2017). Hyperthyroidism and developmental dysfunction. Arch Med 9(4): 6.

34. Dittrich R, Beckmann MW, Oppelt PG, Hoffmann I, Lotz L, Kuwert T \& Mueller A (2011). Thyroid hormone receptors and reproduction. J Reprod Immunol 90(1): 5866.

35. Mansourian AR (2013). Female reproduction physiology adversely manipulated by thyroid disorders: A review of literature. Pak J Biol Sci 16(3): 112-120.

36. Medici M, Ghassabian A, Visser W, Keizer SM, Jaddoe VW, Visser WE \& Bongers JJ (2014). Women with high early pregnancy urinary iodine levels have an increased risk of hyperthyroid newborns: the populationbased G eneration RS tudy. Clin Endocrinol (Oxf). 80(4): 598-606.

37. Seigel SC \& Hodak SP (2012). Thyrotoxicosis. Med Clin 96(2): 175-201.

38. Lee SY, Rhee CM, Leung AM, Braverman LE, Brent GA \& Pearce EN (2015). A review: radiographic iodinated contrast media-induced thyroid dysfunction. J Clinic Endo Met 100(2): 376-383.

39. Kibirige, D, Luzinda K \& Ssekitoleko R (2013). Spectrum of lithium induced thyroid abnormalities: a current perspective. Thyroid Res 6(1): 1-5.

40. Abraham-Nordling M, Bystrom K, Torring O, Lantz M, Berg G, Calissendorff J \& Karlsson FA (2011). Incidence of hyperthyroidism in Sweden. Eur $J$ Endocrinol 165(6): 899.
41. Lee H, Hodi FS, Giobbie-Hurder A, Ott PA, Buchbinder EI, Haq R \& Donahue H (2017). Characterization of thyroid disorders in patients receiving immune checkpoint inhibition therapy. Cancer Immunol Res 5(12): 1133-1140.

42. Deokar PG, Nagdeote AN, Lanje MJ \& Basutkar DG (2016). Prevalence of thyroid disorders in a tertiary care center. Int J Curr Res Rev 8(9): 26.

43. Kahaly GJ, Bartalena L, Hegedus L, Leenhardt L, Poppe K \& Pearce SH (2018). 2018 European thyroid association guideline for the management of Graves' hyperthyroidism. Eur Thyroid J 7(4): 167186.

44. Rahman MA, Biswas MA, Siddika ST, Sikder AM, Talukder SI \& Alamgir MH (2013). Histomorphological pattern of thyroid lesions. Dinajpur Med Col J 6(2): 134-140.

45. Danzi S \& Klein I (2015). Amiodaroneinduced thyroid dysfunction. Case Rep Med 30(4): 179-185.

46. Maggi M, Buvat J, Corona G, Guay A \& Torres LO (2013). Hormonal causes of male sexual dysfunctions and their management (hyperprolactinemia thyroid disorders $\mathrm{GH}$ disorders and DHEA). J Sex Med 10(3): 661-677.

47. Sundaram PS, Padma S, Sudha S \& Sasikala K (2011). Transient cytotoxicity of $131 \mathrm{I}$ beta radiation in hyperthyroid patients treated with radioactive iodine. Indian $\mathrm{J}$ Med Res 133(4): 401.

48. Piantanida E (2017). Preoperative management in patients with Graves' disease. Gland Surg 6(5): 476.

49. Danzi S \& Klein I (2015). Amiodaroneinduced thyroid dysfunction. $J$ Intensive Care Med 30(4): 179-185.

50. Stagnaro-Green A, Abalovich M, Alexander E, Azizi F, Mestman J, Negro R \& Sullivan $S$ (2011). Guidelines of the American Thyroid Association for the diagnosis and management of thyroid disease during pregnancy and postpartum. Thyroid 21(10): 1081-1125.

51. Lithgow K \& Symonds C (2017). Severe thyrotoxicosis secondary to povidone-iodine 
from peritoneal dialysis. Case Rep Endocrinol 17.

52. Antonelli A, Ferrari SM, Corrado A, Domenicantonio A \& Fallahi P (2015). Autoimmune thyroid disorders. Autoimmun Rev 14(2): 174-180.

53. Nandi-Munshi D \& Taplin CE (2015). Thyroid-related neurological disorders and complications in children. Pediatr Neurol 52(4): 373-382.

54. Ogunjobi KO, Ejeh JE, Adedapo KS \& Eniojukan JF (2013). Effectiveness of fixed dose radioactive iodine (RAI) for the treatment of hyperthyroidism: experience of a teaching hospital in South West Nigeria. Mol Imaging Radionucl Ther 22(2): 36.

55. Eftychia GK, Roupas ND \& Markou KB (2017). Effect of excess iodine intake on thyroid on human health. Minerva Med 108(2): 136-146.

56. Cooper DS \& Laurberg P (2013). Hyperthyroidism in pregnancy. Lancet Diabetes Endocrinol 1(3): 238-249.

57. Malhotra S, Kumta S, Bhutada A, Jacobson DE \& Motaghedi R (2016). Topical iodineinduced thyrotoxicosis in a newborn with a Giant Omphalocele. AJP Rep 6(2): e243.

58. Franklyn JA \& Boelaert K (2012). Thyrotoxicosis. Lancet 379(9821): 11551166.

59. Mitrou P, Raptis SA \& Dimitriadis G (2011). Thyroid disease in older people. Maturitas 70(1) 5-9.

60. Hage M, Zantout MS\& Azar ST (2011). Thyroid disorders and diabetes mellitus. $J$ Thyroid Res 201(1).
61. Chung HR (2014). Iodine and thyroid function. Ann Pediatr Endocrinol Metab 19(1): 8.

62. Memon NS, Kazi TG, Afridi HI, Baig JA, Sahito OM, Baloch S \& Waris M (2015). Correlation of manganese with thyroid function in females having hypo-and hyperthyroid disorders. Biol Trace Elem Res 167(2): 165-171.

63. Vissenberg R, Van den BE, Van Wely M, Van der JA, Fliers E, Bisschop PH \& Goddijn M (2012). Treatment of thyroid disorders before conception and in early pregnancy: a systematic review. Hum Reprod 18(4): 360-373.

64. Tay WL, Chng CL, Tien CS, Loke KS, Lam WC, Fook-Chong SM \& Tong AK (2019). High thyroid stimulating receptor antibody titre and large goitre size at first-time radioactive iodine treatment are associated with treatment failure in Graves' disease. Ann Acad Med Singap 48(6): 181-187.

65. Nakatake N, Fukata S \& Tajiri J (2011). Prediction of post-treatment hypothyroidism using changes in thyroid volume after radioactive iodine therapy in adolescent patients with Graves' disease. Intern $J$ Pediatr Endocrinol 1: 14.

66. Papi G, Corsello SM \& Pontecorvi A (2014). Clinical concepts on thyroid emergencies. Front Endocrinol (Lausanne) 5: 102.

67. Singh I \& Hershman JM (2011). Pathogenesis of hyperthyroidism. Comprehensive Physiol 7(1): 67-79.

68. Hartmann K (2015). Thyroid disorders in the oncology patient. J Adv Pract Oncol 6(2): 9. 